\section{Check for updates}

Cite this: New J. Chem., 2021, 45,1404

Received 24th October 2020, Accepted 10th December 2020

DOI: 10.1039/d0nj05231k

rsc.li/njc

\title{
Hierarchically interconnected ZnO nanowires for low-temperature-operated reducing gas sensors: experimental and DFT studies $\dagger$
}

\author{
Parameshwar R. Chikate, (D) a Alfa Sharma, (D) a Sachin R. Rondiya, (D) ${ }^{\mathrm{b}}$ \\ Russell W. Cross, ${ }^{b}$ Nelson Y. Dzade, (iD ${ }^{b}$ Parasharam M. Shirage (D) $^{a}$ and \\ Rupesh S. Devan (D)*a
}

\begin{abstract}
The well-constituted hierarchical arrangement of hexagonal $\mathrm{ZnO}$ nanowires with diameters $<180 \mathrm{~nm}$ and lengths $\sim 5-6 \mu \mathrm{m}$ with clearly visible textural boundaries provided a highly porous film of thickness, $\sim 1300 \mathrm{~nm}$ over a large area. The $\mathrm{ZnO}$ nanowires delivered excellent sensing performance for $\mathrm{CO}$, $\mathrm{C}_{2} \mathrm{H}_{5} \mathrm{OH}$, and $\mathrm{NH}_{3}$ reducing gases at a safe detection limit of $50 \mathrm{ppm}$ at an operating temperature of $100{ }^{\circ} \mathrm{C}$. A maximum response of $115 \%$ and the response and recovery time of 27 and $9 \mathrm{~s}$, respectively, were recorded for toxic $50 \mathrm{ppm} \mathrm{NH}$ gas at the operating temperature of $100{ }^{\circ} \mathrm{C}$, which is better than the performance of various previously reported pristine and doped $\mathrm{ZnO}$ nanostructures. The experimental observations are corroborated by first-principles density functional theory (DFT) calculations, which were performed to determine the reactivity of gas molecules with hexagonal $\mathrm{ZnO}$ nanowires. The expedited sensing response is ascribed to the larger potential barrier offered by the well-interconnected hierarchical growth of hexagonal $\mathrm{ZnO}$ nanowires.
\end{abstract}

\section{Introduction}

In the recent era, smart technologies are necessitating advancement to address safety and security concerns on high priority. The enormous growth of industrialization for luxurious lifestyle has impaired human and environmental health owing to the exhaust of hazardous gases and chemical compounds. Moreover, the dangerous condition of global warming is demanding the early monitoring of air quality and the detection of toxic and explosive gases to control their detrimental effect on the human life and environmental health. The controlled monitoring of harmful gaseous byproducts is urgently required. The involvement of largely generated poisonous carbon monoxide in climate change and the detrimental influence of explosive ethanol $\left(\mathrm{C}_{2} \mathrm{H}_{5} \mathrm{OH}\right)$ and highly toxic ammonia $\left(\mathrm{NH}_{3}\right)$ on health call for immediate detection and monitoring. Nontoxic metal oxides, which deliver excellent electronic mobility along with thermal and chemical stability, are competent candidates to assist in this purpose; however, they suffer from poor selectivity and sensitivity for various gases. The gas

\footnotetext{
${ }^{a}$ Department of Metallurgy Engineering \& Materials Science, Indian Institute of Technology Indore, Simrol, Indore 453552, India. E-mail: rupesh@iiti.ac.in

${ }^{b}$ School of Chemistry, Cardiff University, Cardiff, CF10 3AT, Wales, UK

$\dagger$ Electronic supplementary information (ESI) available. See DOI: 10.1039/ d0nj05231k
}

sensing mechanism, which involves the gas-solid interaction at surfaces, can be improved by providing a large active surface area at nanoscale dimensions. Recent gas sensing approaches have shown that the sensing properties of metal oxides can be significantly enhanced by controlling the nanostructure surface morphologies. ${ }^{1,2}$ The gas sensing performance of various metal oxides, such as $\mathrm{SnO}_{2}, \mathrm{In}_{2} \mathrm{O}_{3}, \mathrm{TiO}_{2}, \mathrm{WO}_{3}, \alpha-\mathrm{Fe}_{2} \mathrm{O}_{3}$, and $\mathrm{ZnO}$, in diverse morphological forms has been investigated. ${ }^{1-3}$ These metal oxides challenge researchers to improve sensing mechanisms due to their higher working temperature, low sensitivity, poor selectivity, short-term stability, and durability. However, ZnO, a widely explored n-type semiconductor with a large bandgap, greater electronic mobility, and ultimate chemical and thermal stability at the nanosize, shows good competency for further improvement in sensing ability., Although the crystal structure, surface morphology, chemical composition, and operating temperature govern the sensing performance of $\mathrm{ZnO}$ nanostructures, doping metals such as $\mathrm{Ag},{ }^{6} \mathrm{Al},{ }^{7} \mathrm{Co},{ }^{8} \mathrm{Cu},{ }^{9} \mathrm{Fe},{ }^{10} \mathrm{Mn},{ }^{11} \mathrm{Pd},{ }^{12} \mathrm{Pt}^{13}$ and $\mathrm{Ta}^{14}$ in $\mathrm{ZnO}$ was adopted to enhance electronic properties for improvement in the gas sensing performance. However, among all explored ZnO nanosize morphologies, one-dimensional (1D) nanostructures deliver large surface-to-volume ratios and continuous pathways for electron transfer, ${ }^{3,15-17}$ which facilitate gas molecule adsorption and prompt electronic transportation in one dimension. 
The working temperature governs the reaction kinetics, conductivity, and electronic movements, which explicitly control the sensing activity of $\mathrm{ZnO}$ nanostructures. ${ }^{18,19}$ Even though the surface redox reaction is activated at high temperature and enhances the reaction kinetics for sensing activity, $\mathrm{ZnO}$ nanostructures have shown prominent gas sensing performance at relatively high temperatures in the range from $300{ }^{\circ} \mathrm{C}$ to $500{ }^{\circ} \mathrm{C}$. ${ }^{20}$ These high working temperatures induce secondary grain growth, causing instability, inaccuracy, high power consumption, and lack of durability in the sensing mechanism. Therefore, reducing the operating temperature range of $\mathrm{ZnO}$ nanostructures is a critical challenge. Significant efforts to develop lower working temperature-based $\mathrm{ZnO}$ gas sensors are prerequisites in light of safety concerns related to these flammable and toxic gases. ZnO-based sensors have detected gases such as $\mathrm{CO}, \mathrm{NH}_{3}, \mathrm{C}_{2} \mathrm{H}_{5} \mathrm{OH}, \mathrm{NO}_{2}, \mathrm{C}_{6} \mathrm{H}_{6}$, and $\mathrm{H}_{2} \mathrm{~S}$; however, prompt and high-sensing responses were achieved only at high working temperatures due to the thermal excitation-driven increase in the surface electrons. Despite the significant effect of the number of grains between interelectrode gaps on the responses of $\mathrm{ZnO}$ nanorods and nanoparticles, the maximum response for $50 \mathrm{ppm} \mathrm{NO}_{2}$ gas (i.e., 44.2) was observed at the temperature of $300{ }^{\circ} \mathrm{C}^{21}$ Moreover, the hierarchical hollow $\mathrm{ZnO}$ microspheres delivered a maximum response at a lower temperature of $275{ }^{\circ} \mathrm{C}$ for various $\mathrm{C}_{2} \mathrm{H}_{5} \mathrm{OH}$ concentrations (8 to $100 \mathrm{ppm}) .^{22}$ Randomly aligned $\mathrm{ZnO}$ nanowires on a patterned $\mathrm{ZnO}: \mathrm{Ga} / \mathrm{SiO}_{2} / \mathrm{Si}$ template delivered a maximum sensor response (22.5\%) at $300{ }^{\circ} \mathrm{C}$ for $1000 \mathrm{ppm} \mathrm{NH}_{3}$ gas, which improved further to $36 \%$ (@1000 ppm) after heavy loading of Pt nanoparticles. ${ }^{23}$ Recently, Colak et al. ${ }^{24}$ observed improvement in the $\mathrm{CO}_{2}$ sensing ability of $\mathrm{ZnO}$ nanorods after doping $\mathrm{Ge}, \mathrm{Nd}$, and $\mathrm{W}$ in lower proportions. However, the maximum sensing response was still observed at a very high temperature of $450{ }^{\circ} \mathrm{C}$. Moreover, the hierarchical $\mathrm{ZnO}$ nanostructures delivered better gas response (i.e. $R_{\mathrm{a}} / R_{\mathrm{g}}=177.1$ ) for $100 \mathrm{ppm}$ $\mathrm{C}_{2} \mathrm{H}_{5} \mathrm{OH}$ at $450{ }^{\circ} \mathrm{C}$ than at room temperature (i.e. $R_{\mathrm{a}} / R_{\mathrm{g}}=$ 24.7). ${ }^{25}$ However, to the best of our knowledge, $\mathrm{ZnO}$ nanostructures have yet to deliver the best performance at a temperature below $150{ }^{\circ} \mathrm{C}$ for sensing $\mathrm{CO}, \mathrm{C}_{2} \mathrm{H}_{5} \mathrm{OH}$, and $\mathrm{NH}_{3}$ gases for possible applications in wearable sensors.

Therefore, here, we demonstrate the gas sensing performance of $\mathrm{ZnO}$ nanowires at lower operating temperatures. The comparative studies illustrate that the $\mathrm{ZnO}$ nanowires synthesized by a cost-effective hydrothermal technique delivered the best sensing performance for $\mathrm{CO}, \mathrm{C}_{2} \mathrm{H}_{5} \mathrm{OH}$, and $\mathrm{NH}_{3}$ gases at a relatively low operating temperature of $100{ }^{\circ} \mathrm{C}$. Sensor responses of $29 \%, 98 \%$, and $115 \%$ were observed for CO, $\mathrm{C}_{2} \mathrm{H}_{5} \mathrm{OH}$, and $\mathrm{NH}_{3}$ gas, respectively, at the operating temperature of $100{ }^{\circ} \mathrm{C}$. Furthermore, response and recovery times of 27 and $9 \mathrm{~s}$ were recorded for toxic $\mathrm{NH}_{3}$ gas at the temperature of $100{ }^{\circ} \mathrm{C}$, respectively, indicating the faster response of $\mathrm{ZnO}$ nanowires to $\mathrm{NH}_{3}$ gas. Furthermore, the experimental observations were validated with electronic structure DFT calculations performed to systematically characterize the reactivities of $\mathrm{CO}, \mathrm{C}_{2} \mathrm{H}_{5} \mathrm{OH}$, and $\mathrm{NH}_{3}$ gases towards the hexagonal ZnO nanowires.

\section{Experimental}

\section{(a) Synthesis and characterization}

The large area arrays of $\mathrm{ZnO}$ nanowires were synthesized using a hydrothermal technique. The reaction of zinc acetate dihydrate $\left(\mathrm{C}_{4} \mathrm{H}_{6} \mathrm{O}_{4} \mathrm{Zn} \cdot 2 \mathrm{H}_{2} \mathrm{O}\right)$ and sodium peroxide $\left(\mathrm{Na}_{2} \mathrm{O}_{2}\right)$ was carried out in an autoclave at an optimized temperature of $85{ }^{\circ} \mathrm{C}$ for $12 \mathrm{~h}$ to grow the $\mathrm{ZnO}$ nanowires over ITO-coated glass substrates hydrothermally. The synthesis protocol of the $\mathrm{ZnO}$ nanowires is akin to that reported in ref. 15 . The surface morphological features of the $\mathrm{ZnO}$ nanowires were substantiated from field emission scanning electron microscopy (FESEM, JEOL, JSM 7610 F Plus). The crystal structure was analyzed using an X-ray diffractometer (D8 Advance, Bruker AXS) with $\mathrm{Cu} \mathrm{k} \alpha$ radiation $(\lambda=1.5405 \AA)$ and a micro-Raman spectrometer (Renishaw InVia system) with $532 \mathrm{~nm}$ incident photons from a diode-pump solid-state laser operated at a minimum power of $17 \mathrm{~mW}$. The chemical analysis of the $\mathrm{ZnO}$ nanowires was revealed from XPS. The gas-sensing performance of the $\mathrm{ZnO}$ nanowires was measured in a home-built setup. ${ }^{26}$ The sensing measurements were performed after exposure to different amounts of reducing gases such as CO, $\mathrm{C}_{2} \mathrm{H}_{5} \mathrm{OH}$, and $\mathrm{NH}_{3}$ gases. Considering that gas adsorption and diffusion are thermally activated processes, the gas sensing performance of the $\mathrm{ZnO}$ nanowires was related to the sensing temperature to identify the optimal working/operational temperature. The sensing behavior was determined for various gas concentrations (i.e., 10, 20, 50, $100 \mathrm{ppm}$ ) at different operation temperatures ranging from $30{ }^{\circ} \mathrm{C}$ (R.T.) to $150{ }^{\circ} \mathrm{C}$ by measuring the changes in the resistance of the $\mathrm{ZnO}$ nanowires in air and gas environments. The gas sensing response $(S \%)$ for the reducing gases was estimated from ref. 7 and 27 .

$$
S(\%)=\left(R_{\text {air }}-R_{\text {gas }}\right) / R_{\text {gas }} \times 100
$$

where $S(\%)$ is the sensor response and $R_{\text {air }}$ and $R_{\text {gas }}$ are the resistance of the sensor material in the air and gas environments, respectively. The response and recovery times were estimated at $90 \%$ of the maximum and minimum resistance values observed for the $\mathrm{ZnO}$ nanowires, respectively, during gas sensing studies. $^{26}$

We also observed variations in sensor resistance values in air when the $\mathrm{ZnO}$ sample was subjected to different temperatures from $30{ }^{\circ} \mathrm{C}$ to $150{ }^{\circ} \mathrm{C}$. The changes in the resistance values of $\mathrm{ZnO}$ are provided in Table 1 . These values are in $\mathrm{k} \Omega$; however, the resistance during the sensing performance is in $\mathrm{M} \Omega$. Therefore, this change in the resistance is not visible in the figures.

Table 1 The change in the resistance $(\mathrm{k} \Omega)$ of $\mathrm{ZnO}$ in the different gas environments to air resistance

Operating temperature

\begin{tabular}{lrrr}
\hline Gas & $50{ }^{\circ} \mathrm{C}$ & $100{ }^{\circ} \mathrm{C}$ & $150{ }^{\circ} \mathrm{C}$ \\
\hline $\mathrm{NH}_{3}$ & 33 & 44 & 30 \\
$\mathrm{C}_{2} \mathrm{H}_{5} \mathrm{OH}$ & 128 & 1325 & 50 \\
$\mathrm{CO}$ & 47 & 182 & 7
\end{tabular}




\section{(b) Computational analysis}

The electronic structure density functional theory (DFT) calculations were performed using the Vienna $A b$ initio Simulation Package (VASP), ${ }^{28}$ wherein the interactions between the core and valence electrons were treated using the Project Augmented Wave (PAW) method. ${ }^{29}$ The electronic wave functions were expanded on a plane-wave basis set with a cutoff energy of $600 \mathrm{eV}$. Geometry optimizations were performed using the conjugate-gradient algorithm until the residual HellmannFeynman forces on all relaxed atoms reached $10^{-3} \mathrm{eV} \AA^{-1}$. The electronic exchange-correlation potential was calculated using the Perdew-Burke-Ernzerhof (PBE) generalized gradient approximation (GGA) functional. ${ }^{30}$ Long-range vdW interactions were accounted for using the method of the Grimme DFT-D3 scheme. ${ }^{31}$ The bulk ZnO was modeled in the hexagonal wurtzite phase, and a $7 \times 7 \times 5$ Monkhorst-Pack $k$-point mesh was used to sample the Brillouin zone. The screened hybrid functional HSE $^{32}{ }^{32}$ was used with an exchange value of $25 \%$ to predict the bandgap accurately. The (1010) surface is generally predicted to be the most stable surface of $\mathrm{ZnO},{ }^{33,34}$ and it is expected to be the most expressed and abundant facet in $\mathrm{ZnO}$ nanocrystals. The $\mathrm{ZnO}$ (1010) surface has been used in previous studies to characterize the interactions of $\mathrm{NO}_{2}, \mathrm{NO}, \mathrm{O}$, and $\mathrm{N}$ species. Therefore, the $\mathrm{ZnO}(10 \overline{1} 0)$ surface was preferred in the present study to describe the adsorption reactions of $\mathrm{CO}$, $\mathrm{C}_{2} \mathrm{H}_{5} \mathrm{OH}$, and $\mathrm{NH}_{3}$ gas molecules. METADISE code ${ }^{35}$ was utilized to ensure the creation of non-dipolar stoichiometric surfaces from optimized bulk wurtzite $\mathrm{ZnO} .^{36}$ The $\mathrm{ZnO}(10 \overline{1} 0)$ surface used to characterize the adsorption reactions of $\mathrm{CO}$, $\mathrm{C}_{2} \mathrm{H}_{5} \mathrm{OH}$, and $\mathrm{NH}_{3}$ gas molecules was created from the optimized bulk ZnO using METADISE code, ${ }^{35}$ which ensures the creation of a surface with a zero dipole moment perpendicular to the surface plane. The gas molecule adsorption calculations were carried out on a $\mathrm{ZnO}(10 \overline{1} 0)-(3 \times 3)$ surface coverage, which is large enough to minimize lateral interactions between the molecules in neighboring image cells. No symmetry constraints were imposed on the structural optimization of the gas- $\mathrm{ZnO}(10 \overline{1} 0)-(3 \times 3)$ systems, and in particular, the molecules were free to move away laterally and vertically from their initial binding sites or reorient themselves to find the lowestenergy adsorption configuration. A $3 \times 3 \times 1 k$-point was used for the surface calculations. Bader charge analysis ${ }^{37}$ was used to quantify any charge transfers between the $\mathrm{ZnO}(10 \overline{1} 0)$ surface and the gas molecules.

\section{Results and discussion}

Fig. 1(a) illustrates the FESEM image of the surface morphology of the large-area arrays of ZnO nanowires grown on ITO-coated glass substrates. The high-magnification FESEM image in the inset of Fig. 1(a) (and Fig. S1 in the ESI $\dagger$ ) confirms that all the hexagonal $\mathrm{ZnO}$ nanowires with clearly visible textural boundaries are confined to diameters of $<180 \mathrm{~nm}$ and lengths of $\sim 5-6 \mu \mathrm{m}$. The well-constituted hierarchical arrangement of $\mathrm{ZnO}$ nanowires provided a highly porous $\sim 1300 \mathrm{~nm}$ thick film over a large area.
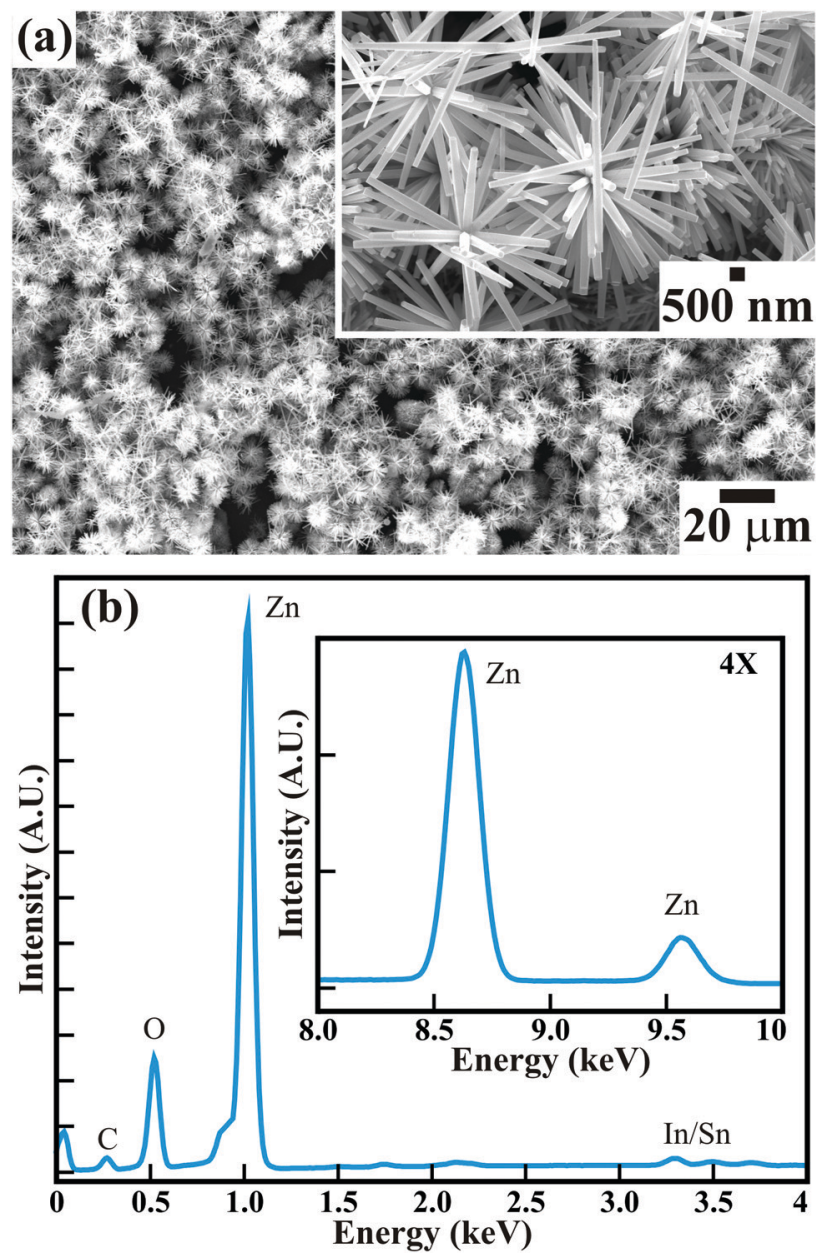

Fig. 1 (a) FESEM image and (b) EDS of large-area arrays of ZnO nanowires grown on ITO-coated glass substrates. The high-magnification FESEM image in the inset of (a) shows the hierarchical growth of the $\mathrm{ZnO}$ nanowires.

The surface morphological appearance of the hexagonal $\mathrm{ZnO}$ nanowires is detailed elsewhere. ${ }^{15}$ The highly porous thin film of single-crystalline $\mathrm{ZnO}$ nanowires is expected to provide distinct gas sensing properties. The energy dispersive X-ray (EDX) spectra of the $\mathrm{ZnO}$ nanowires (Fig. 1(b)) corroborates the presence of $\mathrm{Zn}$ and $\mathrm{O}$ elements in the array of hexagonal $\mathrm{ZnO}$ nanowires. The presence of In and $\mathrm{Sn}$ is confirmed with small peaks. Moreover, the presence of a relatively very small peak of $\mathrm{C}$ confirms the presence of a negligible amount of $\mathrm{C}$ over the surface of the ZnO nanowires array. X-ray photoelectron spectroscopy (XPS) confirmed the formation of stoichiometric $\mathrm{ZnO}$ nanowires. The XPS analysis (not provided here) is very much akin to that in our studies reported earlier. ${ }^{15}$ The phase purity and crystal structure of the as-synthesised $\mathrm{ZnO}$ nanowires analyzed from X-ray diffraction (XRD) studies (ESI $\dagger$ ) confirmed the growth of hexagonal wurtzite ZnO nanowires without any defects or impurity phases. Therefore, the present hexagonal $\mathrm{ZnO}$ nanowires with a high degree of crystallinity were expected to enable better sensing response for hazardous and toxic gases such as $\mathrm{CO}, \mathrm{C}_{2} \mathrm{H}_{5} \mathrm{OH}$, $\mathrm{NH}_{3}$, etc. 
Raman scattering was performed at room temperature to investigate the vibrational properties of the $\mathrm{ZnO}$ nanowires. Fig. 2 shows five prominent Raman active bands, which are $\mathrm{A}_{1}+$ $\mathrm{E}_{1}+2 \mathrm{E}_{2}$ Raman active modes as explained by group theory, where $A_{1}$ and $E_{1}$ are the Raman and infrared active polar modes and $\mathrm{E}_{2}$ is the Raman active nonpolar mode. The Raman bands observed at $328,373,431,530$, and $576 \mathrm{~cm}^{-1}$ are assigned to the $\mathrm{A}_{1}, \mathrm{~A}_{1}, \mathrm{E}_{2}, \mathrm{~A}_{1}$, and $\mathrm{E}_{1}$ modes of wurtzite $\mathrm{ZnO}$, respectively. ${ }^{38-40}$ The peak around $373 \mathrm{~cm}^{-1}$ is ascribed to the transverse optical $A_{1}$ mode resulted from the polarized $A_{1}$ and $E_{1}$ modes of the vibrations. A highly intense Raman band at $431 \mathrm{~cm}^{-1}$ is assigned to the high crystallinity of the hexagonal $\mathrm{ZnO}$ nanowires array. ${ }^{41}$ The Raman band at $576 \mathrm{~cm}^{-1}$ corresponds to the $\mathrm{E}_{1}$ mode for the presence of oxygen vacancies and interstitial oxygen as well as the complexes of $\mathrm{Zn} .{ }^{42}$ However, the relatively low intensity indicates that the $\mathrm{ZnO}$ nanowires exhibit a smaller amount of oxygen vacancies. Moreover, the red shifting of the Raman bands in the ZnO nanowires (Table S1, ESI $\dagger$ ) compared to those of other reported nanostructure morphologies and the bulk wurtzite structure of $\mathrm{ZnO}$ indicate phonon confinement. This reconfirms that the hexagonal wurtzite $\mathrm{ZnO}$ nanowires grown on ITO-coated glass substrates are highly crystalline with the lower amount of oxygen deficiencies.

The temperature-dependent sensing performance of the $\mathrm{ZnO}$ nanowire arrays was performed for various concentrations of $\mathrm{CO}, \mathrm{C}_{2} \mathrm{H}_{5} \mathrm{OH}$, and $\mathrm{NH}_{3}$ reducing gases. The optimized gas sensing performance was confirmed in resistive mode. Fig. 3 shows the temperature-dependent real-time dynamic resistance response transients of the $\mathrm{ZnO}$ nanowires for 10 to $100 \mathrm{ppm}$ of CO. Sequential exposure of 10, 20, 50, and $100 \mathrm{ppm}$ CO to $\mathrm{ZnO}$ nanowires maintained at room temperature (i.e., $30{ }^{\circ} \mathrm{C}$ ) confirmed the cyclic variation in the resistance. A similar trend was observed in the resistance variation when the $\mathrm{ZnO}$ nanowires were maintained at temperatures of $50{ }^{\circ} \mathrm{C}, 100{ }^{\circ} \mathrm{C}$, and $150{ }^{\circ} \mathrm{C}$. The resistance of the $\mathrm{ZnO}$ nanowires was reduced with increasing $\mathrm{CO}$ concentration and was further altered with temperature

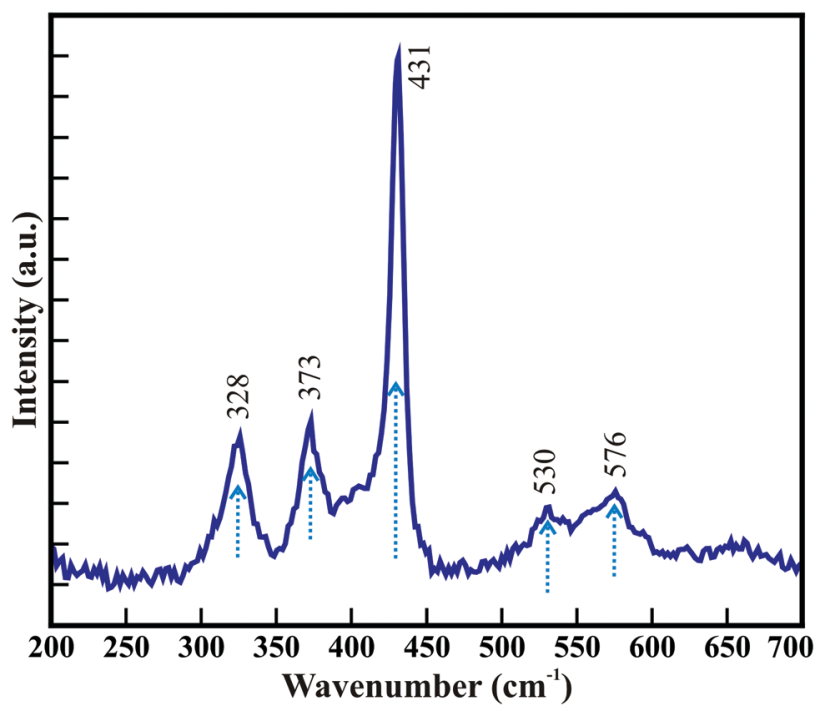

Fig. 2 Raman spectra of hexagonal $\mathrm{ZnO}$ nanowires. variation. Fig. 3(b) illustrates the influence of temperature and $\mathrm{CO}$ concentration on the sensing response of the $\mathrm{ZnO}$ nanowires. The sensing response of the $\mathrm{ZnO}$ nanowires improved with increasing concentration of CO from 10 to $100 \mathrm{ppm}$ for all studied temperatures. Even though the best response was observed for $100 \mathrm{ppm}$, the most compelling response was estimated for the $20 \mathrm{ppm}$ CO. The best responses of $17.4 \%$, $23.6 \%, 31.6 \%$, and $28.3 \%$ were observed for $100 \mathrm{ppm} \mathrm{CO}$, and relatively compelling responses of $11.5 \%, 13.7 \%, 30.3 \%$, and $20.2 \%$ were observed for $20 \mathrm{ppm} \mathrm{CO}$ when the $\mathrm{ZnO}$ nanowires were maintained at temperatures of $30{ }^{\circ} \mathrm{C}, 50{ }^{\circ} \mathrm{C}, 100{ }^{\circ} \mathrm{C}$ and $150{ }^{\circ} \mathrm{C}$, respectively. However, the temperature-influenced sensing response was effective for all the concentrations of CO. The response improved with increasing temperature and was reduced at higher temperatures beyond $150{ }^{\circ} \mathrm{C}$ after achieving the maximum response at $100{ }^{\circ} \mathrm{C}$ (Fig. 3(b)). A fitted logarithmic plot between the response $(S \%)$ and gas concentration (Fig. 3(c)) illustrates the gas detection limit of the $\mathrm{ZnO}$ nanowires. The estimated detection limit for CO shows a progressive decrease of $3.57,1.07,1$, and $1.02 \mathrm{ppm}$ with increasing operating temperature from $30{ }^{\circ} \mathrm{C}$ to $150{ }^{\circ} \mathrm{C}$, respectively. ${ }^{43}$ The highest responses of $26.2 \%, 30.3 \%, 31.9 \%$, and $31.6 \%$ were observed for 10, 20, 50, and 100 ppm CO (Fig. 3(d)), respectively, at a temperature of $100{ }^{\circ} \mathrm{C}$. The saturation of the adsorption and desorption reaction processes may have resulted in the steady response above $50 \mathrm{ppm}$. The response and recovery times estimated at $100{ }^{\circ} \mathrm{C}$ were 25.0 and $17.5 \mathrm{~s}$ for $50 \mathrm{ppm} \mathrm{CO}$ and 15.1 and $12.5 \mathrm{~s}$ for $100 \mathrm{ppm} \mathrm{CO}$, which are superior (Table S2, $\mathrm{ESI} \dagger)$. Furthermore, the $\mathrm{ZnO}$ nanowires showed better sensing response at $100{ }^{\circ} \mathrm{C}$ for $50 \mathrm{ppm} \mathrm{CO}$ by delivering a maximum response of $31.9 \%$. The hexagonal $\mathrm{ZnO}$ nanowires exhibited excellent and faster response within the detection safety limit for $\mathrm{CO}$ (i.e., $\sim 50 \mathrm{ppm}$ ) at relatively very low temperatures compared to the pristine and metal-doped $\mathrm{ZnO}$ nanostructures, as listed in Table S3 (ESI $\dagger$ ).

Likewise, Fig. 4 shows the temperature-dependent real-time dynamic resistance response transients of the $\mathrm{ZnO}$ nanowires for 10 to $100 \mathrm{ppm}$ of $\mathrm{C}_{2} \mathrm{H}_{5} \mathrm{OH}$. A sequential assortment of 10 , 20,50 , and $100 \mathrm{ppm} \mathrm{C}_{2} \mathrm{H}_{5} \mathrm{OH}$ at room temperature (i.e., $30{ }^{\circ} \mathrm{C}$ ) confirmed the cyclic variation in the resistance, akin to that observed for CO gas. Similar behavior was observed at $50{ }^{\circ} \mathrm{C}$, $100{ }^{\circ} \mathrm{C}$, and $150{ }^{\circ} \mathrm{C}$. The resistance of the $\mathrm{ZnO}$ nanowires was reduced with increasing concentration of $\mathrm{C}_{2} \mathrm{H}_{5} \mathrm{OH}$ and was further altered after varying the temperature. Fig. 4(b) illustrates the influence of temperature and $\mathrm{C}_{2} \mathrm{H}_{5} \mathrm{OH}$ concentration on the sensing response of the $\mathrm{ZnO}$ nanowires. The sensing response is influenced remarkably by the temperature for all concentrations of $\mathrm{C}_{2} \mathrm{H}_{5} \mathrm{OH}$ studied. The response improved with increasing temperature but decreased for higher temperatures (i.e., $150{ }^{\circ} \mathrm{C}$ ) after achieving a maximum response at $100{ }^{\circ} \mathrm{C}$ for all the $\mathrm{C}_{2} \mathrm{H}_{5} \mathrm{OH}$ concentrations. The best sensing response for all the concentrations of $\mathrm{C}_{2} \mathrm{H}_{5} \mathrm{OH}$ was observed at the temperature of $100{ }^{\circ} \mathrm{C}$. Response values of $55.7 \%, 63.2 \%, 101.9 \%$, and $82.8 \%$ were observed for $10,20,50$, and $100 \mathrm{ppm} \mathrm{C}_{2} \mathrm{H}_{5} \mathrm{OH}$, respectively, at the temperature of $100{ }^{\circ} \mathrm{C}$. The sensing response of the $\mathrm{ZnO}$ nanowires improved with increasing concentration of $\mathrm{C}_{2} \mathrm{H}_{5} \mathrm{OH}$. 

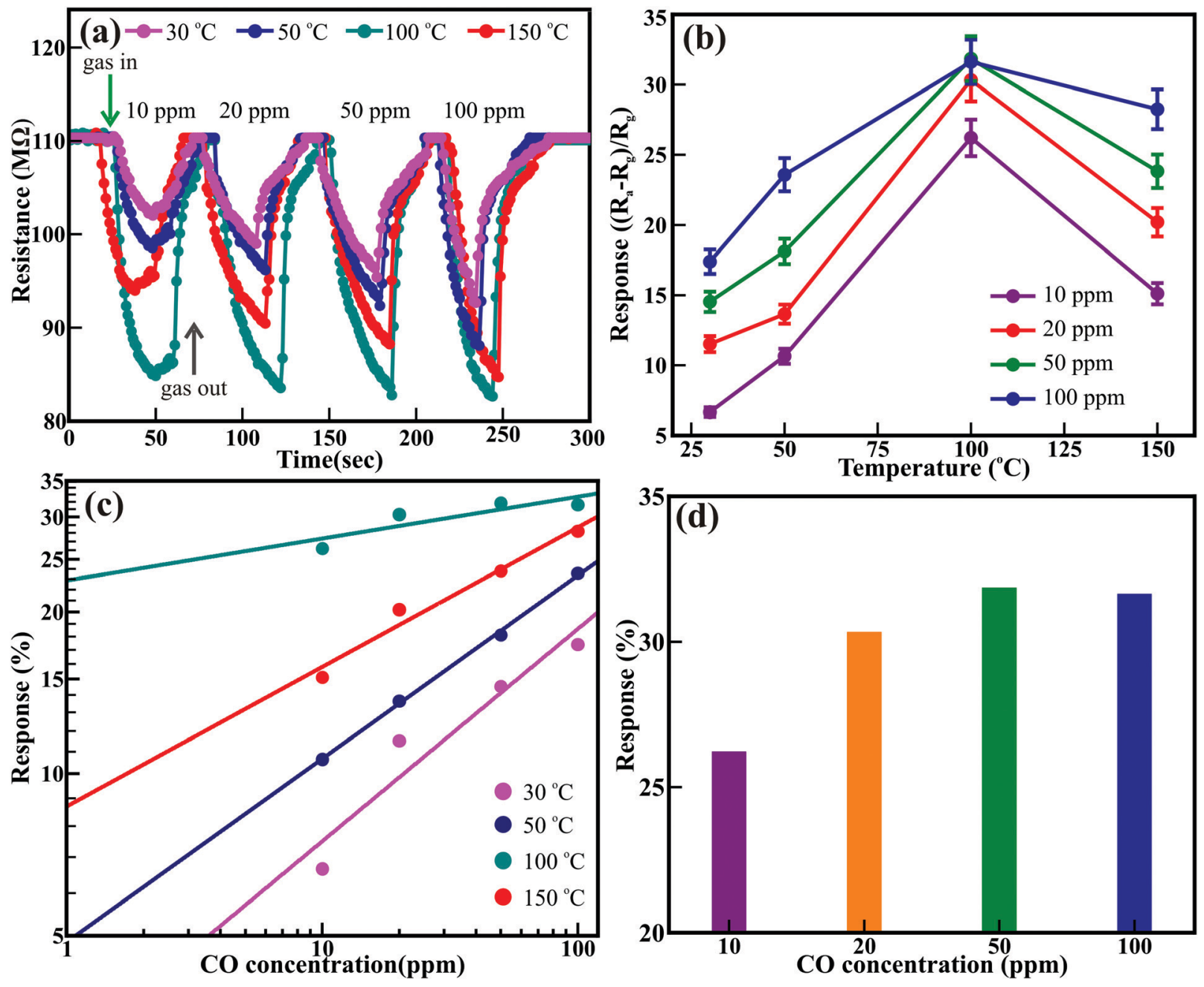

Fig. 3 (a) Time-dependent response-recovery behavior of $\mathrm{ZnO}$ nanowires with different concentrations of $\mathrm{CO}$ gas at various operating temperatures (i.e., $30{ }^{\circ} \mathrm{C}, 50^{\circ} \mathrm{C}, 100{ }^{\circ} \mathrm{C}$ and $150{ }^{\circ} \mathrm{C}$ ). (b) Temperature-dependent response behavior of $\mathrm{ZnO}$ nanowires with different concentrations of $\mathrm{CO}$ gas. (c) $\mathrm{CO}$ concentration-dependent response behavior of $\mathrm{ZnO}$ nanowires at different operating temperatures. (d) The optimum sensing response of the $\mathrm{ZnO}$ nanowires sensor as a function of $\mathrm{CO}$ concentration at the operating temperature of $100{ }^{\circ} \mathrm{C}$.

The highest sensing responses of $58.4 \%, 73.7 \%, 101.9 \%$, and $86.9 \%$ were observed at the temperatures of $30{ }^{\circ} \mathrm{C}, 50{ }^{\circ} \mathrm{C}, 100{ }^{\circ} \mathrm{C}$, and $150{ }^{\circ} \mathrm{C}$, respectively, after exposing the $\mathrm{ZnO}$ nanowires to $50 \mathrm{ppm} \mathrm{C}_{2} \mathrm{H}_{5} \mathrm{OH}$. The reason for the reduction in the response at higher temperature $\left(>100{ }^{\circ} \mathrm{C}\right)$ is not well understood; however, the saturation of adsorption and faster desorption reaction processes may be the origin of this effect. The detection limit of the $\mathrm{ZnO}$ nanowire sensor for $\mathrm{C}_{2} \mathrm{H}_{5} \mathrm{OH}$ gas was estimated from the linear fitting of the $\log -\log$ plot of the response and gas concentration, as shown in Fig. 4(c). Detection limits of 4.98, $1.34,1.01$, and $1.02 \mathrm{ppm}$ were observed as the operating temperature increased from $30{ }^{\circ} \mathrm{C}$ to $150{ }^{\circ} \mathrm{C}$, respectively. Moreover, the response and recovery times estimated for 50 ppm $\mathrm{C}_{2} \mathrm{H}_{5} \mathrm{OH}$ at $100{ }^{\circ} \mathrm{C}$ are 40.3 and 19.4 s., respectively, which are relatively more significant than those of $\mathrm{ZnO}$ nanorods (53 and $48 \mathrm{~s}$ for $50 \mathrm{ppm}$ at $\left.340{ }^{\circ} \mathrm{C}\right) .{ }^{44}$ Overall, the $\mathrm{ZnO}$ nanowires showed better sensitivity at $100{ }^{\circ} \mathrm{C}$ for the $50 \mathrm{ppm} \mathrm{C}_{2} \mathrm{H}_{5} \mathrm{OH}$ by delivering a maximum response of $101.9 \%$ (Fig. 4 (d)). This sensing response of $\mathrm{ZnO}$ nanowires is very high at a relatively low temperature compared to the responses of pristine, doped, and decorated $\mathrm{ZnO}$ nanostructures, as listed in Table S4 (ESI $\dagger$ ). Moreover, the $\mathrm{ZnO}$ nanowires delivered better responses than the values reported by Guo et al. ${ }^{45}$ for $\mathrm{ZnO}$ nanowires (i.e., $3.7 \%$ at $380{ }^{\circ} \mathrm{C}$ ), which achieved a value of $33.6 \%$ (@380 ${ }^{\circ} \mathrm{C}$ ) after functionalization with $\mathrm{Au}$ nanoparticles. ${ }^{48}$ Wang et al. reported that hydrothermally synthesized $\mathrm{ZnO}$ nanorods provided a maximum response of $\sim 22 \%$ for $50 \mathrm{ppm}$ at $320{ }^{\circ} \mathrm{C}$ but did not respond below $200{ }^{\circ} \mathrm{C} .{ }^{44}$ Although Al-doped $\mathrm{ZnO}$ nanostructures embedded in multi-microstructures delivered a sensing response of $\sim 40 \%$ at $160{ }^{\circ} \mathrm{C}$, the exceptionally high exposure of 3000 ppm $\mathrm{C}_{2} \mathrm{H}_{5} \mathrm{OH}$ played a significant role and strongly influenced this gain. ${ }^{46}$

Subsequently, the ZnO nanowires arrays were subjected to $\mathrm{NH}_{3}$ gas sensing. Fig. 5 shows the real-time dynamic resistance response transients of the $\mathrm{ZnO}$ nanowires in a controlled $\mathrm{NH}_{3}$ atmosphere (i.e., 10 to $100 \mathrm{ppm}$ ) at various temperatures. Sequential exposure to 10, 20, 50, and $100 \mathrm{ppm} \mathrm{NH}_{3}$ gas atmosphere at room temperature (i.e., $30{ }^{\circ} \mathrm{C}$ ) confirmed distinct 

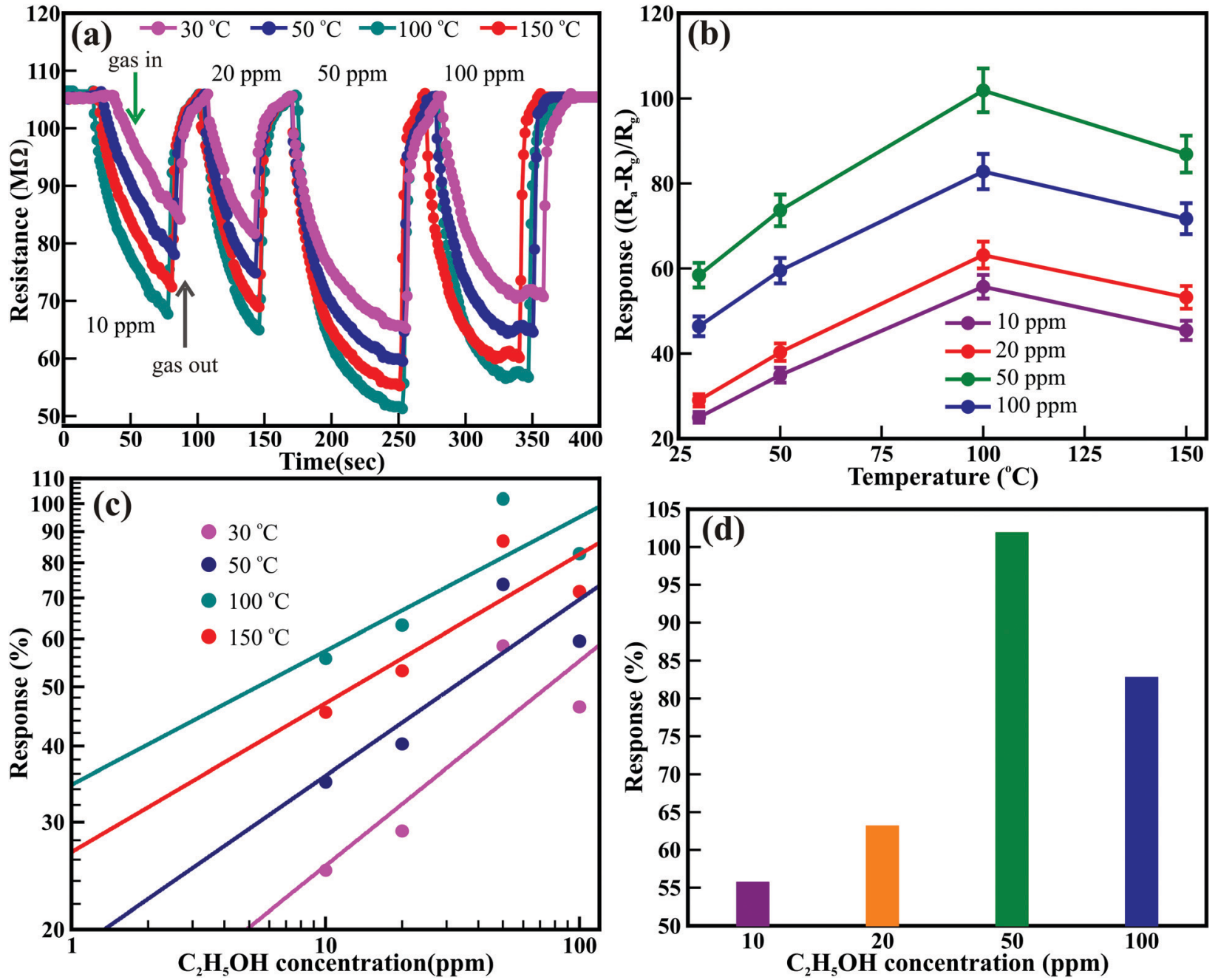

Fig. 4 (a) Time-dependent response-recovery behavior of $\mathrm{ZnO}$ nanowires with different concentrations of $\mathrm{C}_{2} \mathrm{H}_{5} \mathrm{OH}$ gas at various operating temperatures (i.e., $30{ }^{\circ} \mathrm{C}, 50{ }^{\circ} \mathrm{C}, 100{ }^{\circ} \mathrm{C}$ and $150{ }^{\circ} \mathrm{C}$ ). (b) Temperature-dependent response behavior of ZnO nanowires with different concentrations of $\mathrm{C}_{2} \mathrm{H}_{5} \mathrm{OH}$ gas. (c) $\mathrm{C}_{2} \mathrm{H}_{5} \mathrm{OH}$ concentration-dependent response behavior of $\mathrm{ZnO}$ nanowires at different operating temperatures. (d) The optimum sensing response of the $\mathrm{ZnO}$ nanowires sensor as a function of $\mathrm{C}_{2} \mathrm{H}_{5} \mathrm{OH}$ concentration at the operating temperature of $100{ }^{\circ} \mathrm{C}$.

variations in the resistance (Fig. 5(a)) akin to those observed for $\mathrm{C}_{2} \mathrm{H}_{5} \mathrm{OH}$ and $\mathrm{CO}$ gases. The resistance of the $\mathrm{ZnO}$ nanowires was reduced with increasing $\mathrm{NH}_{3}$ gas concentration. A similar trend was observed for $50{ }^{\circ} \mathrm{C}, 100{ }^{\circ} \mathrm{C}$, and $150{ }^{\circ} \mathrm{C}$ in addition to the significant decrease in the resistance with changing temperature. Fig. 5(b) illustrates the effects of the temperature and concentration of $\mathrm{NH}_{3}$ gas on the sensing performance of the $\mathrm{ZnO}$ nanowires. The sensing response is influenced by temperature irrespective of the variation in the concentration of $\mathrm{NH}_{3}$. The response was enhanced with increasing temperature but decreased after achieving the maximum response at $100{ }^{\circ} \mathrm{C}$ for all the concentrations. The best responses of $105.5 \%$, $109.7 \%, 115.9 \%$, and $128.9 \%$ were observed for $10,20,50$, and $100 \mathrm{ppm} \mathrm{NH}_{3}$, respectively, at a constant temperature of $100{ }^{\circ} \mathrm{C}$. Moreover, the sensing response increased with increasing $\mathrm{NH}_{3}$ concentration irrespective of temperature. Higher sensing responses of $71.0 \%, 85.7 \%, 128.9 \%$, and $103.5 \%$ were observed after exposing the $\mathrm{ZnO}$ nanowires to $100 \mathrm{ppm} \mathrm{NH}_{3}$ at temperatures of $30,50,100$, and $150{ }^{\circ} \mathrm{C}$, respectively. However, the $\mathrm{ZnO}$ nanowires showed excellent response at $100{ }^{\circ} \mathrm{C}$ irrespective of the concentration of $\mathrm{NH}_{3}$. The maximum responses of $115.9 \%$ and $128.9 \%$ were observed at $100{ }^{\circ} \mathrm{C}$ for 50 and $100 \mathrm{ppm} \mathrm{NH}$, respectively (Fig. 5(d)). Detection limits of 5.93, $1.02,1.01$, and $1.02 \mathrm{ppm}$ were estimated for $\mathrm{NH}_{3}$ gas at the operating temperatures of $30,50,100$, and $150{ }^{\circ} \mathrm{C}$, respectively (Fig. 5(c)). The estimated response and recovery times at $100{ }^{\circ} \mathrm{C}$ were 18.3 and $10.8 \mathrm{~s}$ for $50 \mathrm{ppm} \mathrm{NH}$ and 20.7 and $13.5 \mathrm{~s}$ and $100 \mathrm{ppm} \mathrm{NH}_{3}$ which are better than those of various $\mathrm{ZnO}$ nanostructures reported in the literature (Table S5, ESI $\dagger$ ). This confirms that the $\mathrm{ZnO}$ nanowires deliver a faster response to $\mathrm{NH}_{3}$ than to $\mathrm{C}_{2} \mathrm{H}_{5} \mathrm{OH}$ and $\mathrm{CO}$ gases. Moreover, the hexagonal $\mathrm{ZnO}$ nanowires delivered excellent response to $\mathrm{NH}_{3}$ gas at a lower temperature (i.e., $100{ }^{\circ} \mathrm{C}$ ) than those of the various pristine and metal-doped $\mathrm{ZnO}$ nanostructures mentioned in Table S6 (ESI $\dagger$ ). Recently, Tharsika et $a{ }^{47}{ }^{47}$ revealed a sensing response of $285 \%$ toward $400 \mathrm{ppm} \mathrm{NH}_{3}$ at $400{ }^{\circ} \mathrm{C}$ for $\mathrm{ZnO}$ 

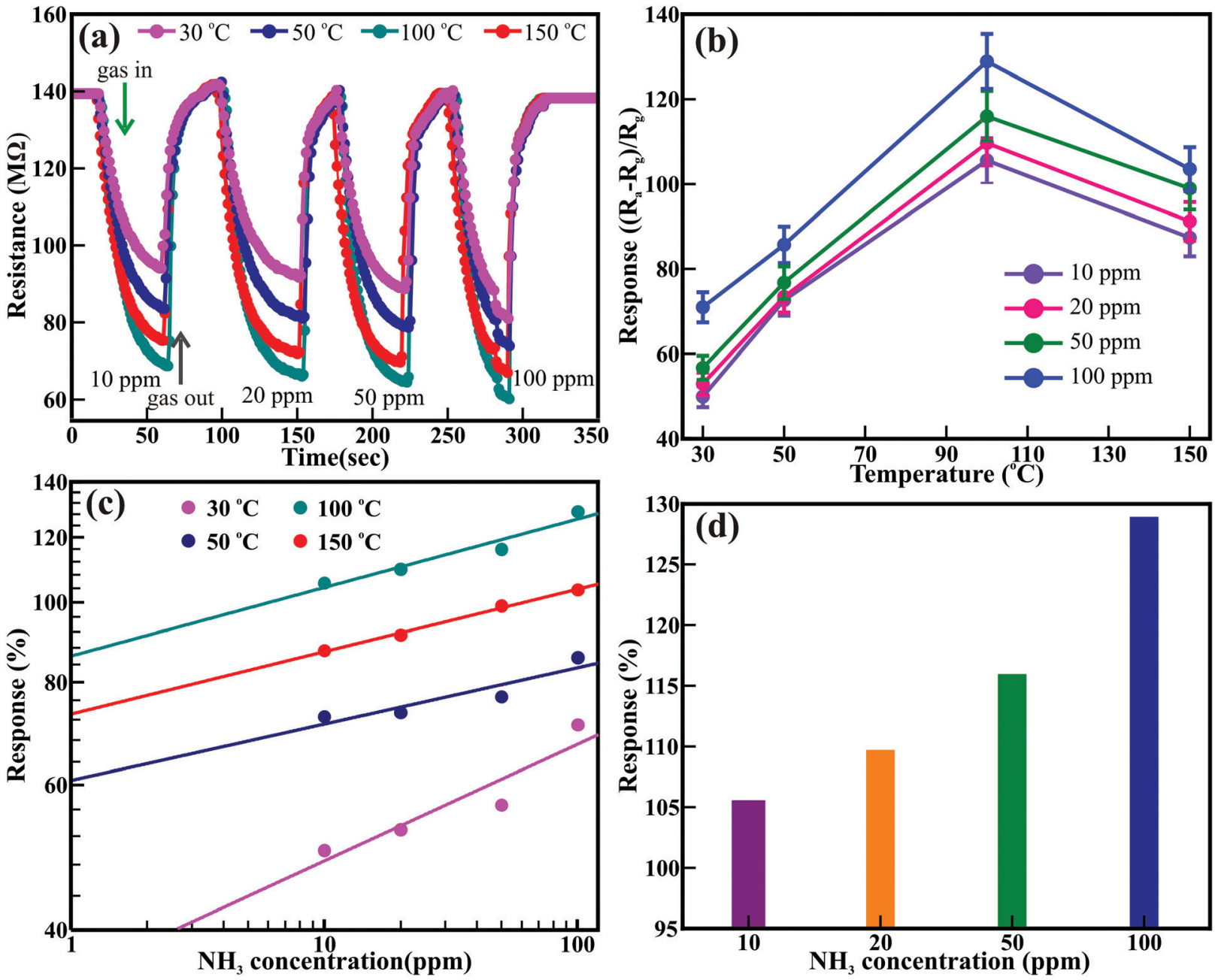

Fig. 5 (a) Time-dependent response-recovery behavior of $\mathrm{ZnO}$ nanowires with different concentrations of $\mathrm{NH}_{3}$ gas at various operating temperatures (i.e., 30, 50, 100 and $150{ }^{\circ} \mathrm{C}$ ). (b) Temperature-dependent response behavior of $\mathrm{ZnO}$ nanowires with different concentrations of $\mathrm{NH}_{3}$ gas. (c) $\mathrm{NH}_{3}$ concentration-dependent response behavior of $\mathrm{ZnO}$ nanowires at different operating temperatures. (d) The optimum sensing response of the $\mathrm{ZnO}$ nanowires sensor as a function of $\mathrm{NH}_{3}$ concentration at the operating temperature of $100{ }^{\circ} \mathrm{C}$.

nanorods deposited over $\mathrm{SnO}_{2}$ thin film; however, reduction in the concentration of $\mathrm{NH}_{3}$ enormously reduced the response. $\mathrm{Li}$ et al. ${ }^{47}$ reported a sensor response of $57.5 \%$ for $600 \mathrm{ppm} \mathrm{NH}_{3}$ at $150{ }^{\circ} \mathrm{C}$ using $\mathrm{ZnO}$ nanoparticles; however, the response was reduced to $18 \%$ for $50 \mathrm{ppm}$.

Fig. 6 presents the histogram of the most effective sensing performance (Fig. 6(a)) and selectivity performance (Fig. 6(b)) of the $\mathrm{ZnO}$ nanowires at the optimal working temperature of $100{ }^{\circ} \mathrm{C}$ for the $\mathrm{CO}, \mathrm{C}_{2} \mathrm{H}_{5} \mathrm{OH}$, and $\mathrm{NH}_{3}$ gases. The selectivity of a sensor describes its ability to differentiate a specific target gas from other interfering gases. The selectivity parameter $(\beta)$ is generally defined as $^{48} \beta=S_{\text {interfering }} / S_{\text {target }}$, where $S_{\text {target }}$ and $S_{\text {interfering }}$ are the response of the target gas $\left(\mathrm{NH}_{3}\right)$ and other gases $\left(\mathrm{CO}\right.$ and $\left.\mathrm{C}_{2} \mathrm{H}_{5} \mathrm{OH}\right)$, respectively. The estimated selectivity parameter is shown in Fig. 6(b). The value of $\beta$ lies within the $0.24-0.88$ range, where maximum values of 0.88 and 0.27 were obtained for $50 \mathrm{ppm}$ concentrations of $\mathrm{C}_{2} \mathrm{H}_{5} \mathrm{OH}$ and $\mathrm{CO}$ gases, respectively, at the optimum temperature of $100{ }^{\circ} \mathrm{C}$. The hexagonal $\mathrm{ZnO}$ nanowires delivered the best response for the detection safety limit (i.e., $\sim 50 \mathrm{ppm}$ ) of all the studied gases at $100{ }^{\circ} \mathrm{C}$, assigned to the deactivation of desorption and diffusion reaction processing, and inefficient adsorption and faster desorption below and above $100{ }^{\circ} \mathrm{C}$, respectively. ${ }^{50}$ Moreover, the adsorption and desorption of the oxygen species transformed the resistance of the $\mathrm{ZnO}$ nanowires with increasing temperature and dramatically controlled the response. Pristine ZnO nanostructures seldom offer perfect $\mathrm{NH}_{3}$ sensing performance, except at higher temperatures. Although a few studies have reported the sensing response of $\mathrm{ZnO}$ to $\mathrm{NH}_{3}$, a suitable response was obtained either at higher temperatures or after doping with metals (Table S6, ESI $\dagger$ ). The ZnO nanowires in the present work delivered the highest response to $\mathrm{NH}_{3}$ at $100{ }^{\circ} \mathrm{C}$, which can be attributed to the well-defined hexagonal morphology, clearly visible textural boundaries, single-crystalline nature, and good interconnections of the nanowires owing to their hierarchical arrangement.

To gain further atomic-level insights into the gas sensing response of the $\mathrm{ZnO}$ nanowires, we performed first-principles 

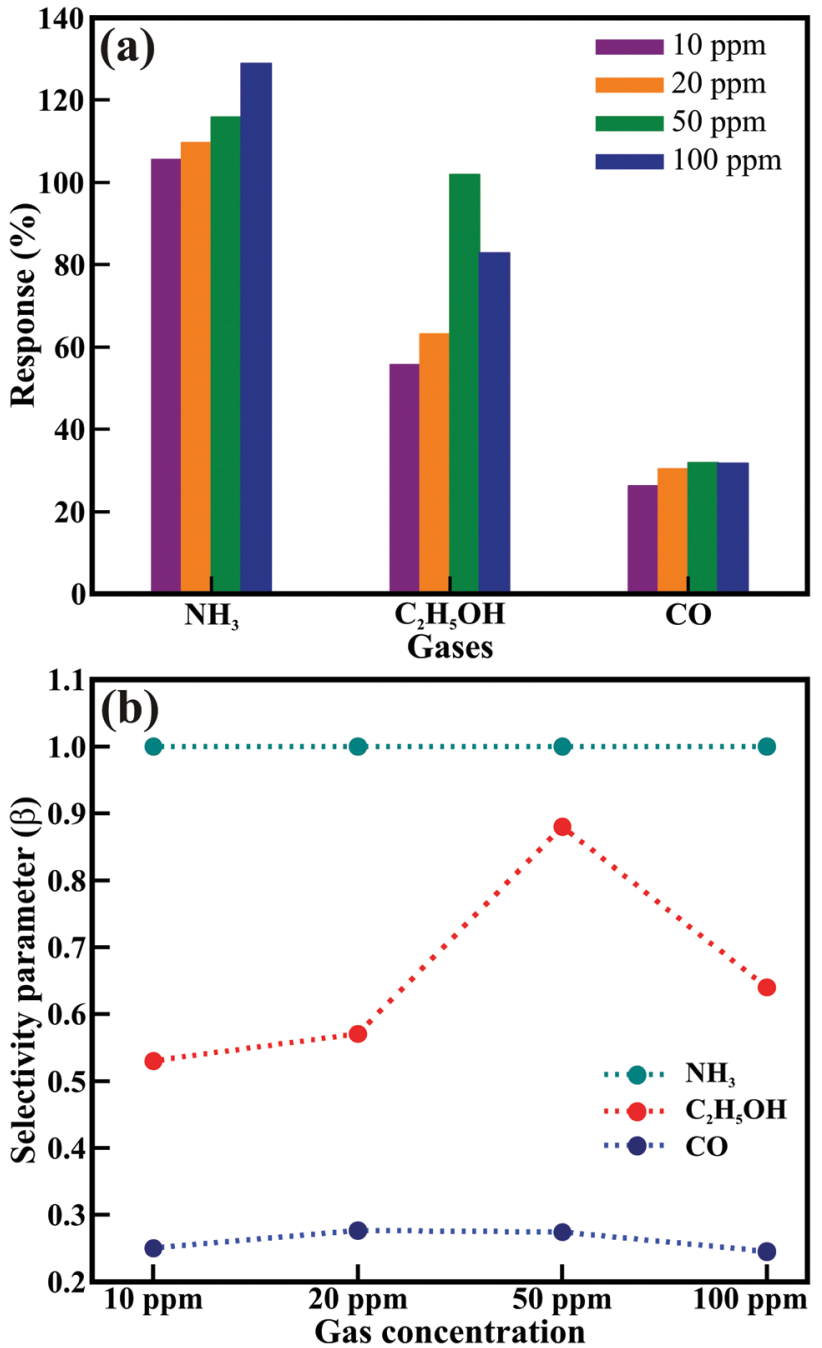

Fig. 6 (a) Histogram of the maximum sensor response and (b) variations in the selectivity parameter $(\beta)$ of the $\mathrm{ZnO}$ nanowires sensor for $50 \mathrm{ppm}$ $\mathrm{CO}, \mathrm{C}_{2} \mathrm{H}_{5} \mathrm{OH}$, and $\mathrm{NH}_{3}$ gases at an operating temperature of $100{ }^{\circ} \mathrm{C}$.

DFT simulations of the adsorption reactions between $\mathrm{CO}$, $\mathrm{C}_{2} \mathrm{H}_{5} \mathrm{OH}$, and $\mathrm{NH}_{3}$ molecules and the $\mathrm{ZnO}$ (1010) surface. Before investigating the adsorption reactions, the bulk $\mathrm{ZnO}$ was modeled in the hexagonal wurtzite phase with space group $P 63 m c$ (no. 186), as shown in Fig. 7(a). The fully optimized lattice parameters predicted of $a=b=3.275 \AA$ and $c=5.284 \AA$ were in excellent agreement with experimentally observed lattice parameters. The partial density of states (Fig. 7(b)) reveals that the valence and conduction band edges are dominated by the $\mathrm{O}(2 \mathrm{p})$ states with a small contribution from the $\mathrm{Zn}(3 \mathrm{~d})$ states. The bandgap of $3.24 \mathrm{eV}$ predicted from the screened hybrid HSE06 functional ${ }^{51}$ is consistent with experimentally reported values for $\mathrm{ZnO} .{ }^{4}$ Considering the key role of surface oxygen species in the gas response process over the $\mathrm{ZnO}$ surface, the adsorption of oxygen molecules on $\mathrm{ZnO}(10 \overline{1} 0)$ surface was first explored and was found to preferentially adsorb dissociatively, as shown in Fig. 7(c). The Bader population shows that the dissociated $\mathrm{O}$ atoms gained $0.87 \mathrm{e}^{-}$each from the interacting surface $\mathrm{Zn}$ sites, resulting in the formation of $2 \mathrm{O}^{-}$species. The adsorption energy $\left(E_{\text {ads }}\right)$ of the gas molecules, which gives a measure of the strength of the gas-ZnO interactions, was calculated as $E_{\text {ads }}=E_{\text {surf }+ \text { gas }}-\left(E_{\text {surf }}+E_{\text {gas }}\right)$, where $E_{\text {surf+gas }}$ is the total energy of the surface and gas system in the equilibrium state, $E_{\text {surf }}$ is the total energy of the isolated oxygen-covered $\mathrm{O}_{2} / \mathrm{ZnO}(10 \overline{1} 0)$ surface and $E_{\text {gas }}$ is the total energy of the isolated gas molecules. Accordingly, a negative value of $E_{\text {ads }}$ indicates exothermic and stable adsorption, whereas a positive value indicates unstable adsorption. The lowest-energy adsorption configurations of $\mathrm{CO}, \mathrm{C}_{2} \mathrm{H}_{5} \mathrm{OH}$, and $\mathrm{NH}_{3}$ gas molecules are shown in Fig. $7(\mathrm{~d}-\mathrm{f})$. The CO molecule released the least adsorption energy of $-1.35 \mathrm{eV}$ compared to $\mathrm{C}_{2} \mathrm{H}_{5} \mathrm{OH}$ and $\mathrm{NH}_{3}$, which released adsorption energies of -1.87 and $-2.11 \mathrm{eV}$, respectively; this indicates that the order of the binding strength is $\mathrm{CO}<\mathrm{C}_{2} \mathrm{H}_{5} \mathrm{OH}<\mathrm{NH}_{3}$. The stronger binding of $\mathrm{NH}_{3}$ is consistent with the observed higher maximum response from the $\mathrm{ZnO}$ nanowires. From the Bader charge analyses, the adsorption of $\mathrm{CO}, \mathrm{C}_{2} \mathrm{H}_{5} \mathrm{OH}$, and $\mathrm{NH}_{3}$ on the $\mathrm{O}_{2}$ / $\mathrm{ZnO}(10 \overline{10})$ surface demonstrate that the $\mathrm{CO}$ molecule acts as a charge acceptor, withdrawing $0.58 \mathrm{e}^{-}$from the surface after adsorption, whereas the $\mathrm{C}_{2} \mathrm{H}_{5} \mathrm{OH}$ and $\mathrm{NH}_{3}$ molecules act as charge donors, transferring approximately 0.02 and $0.08 \mathrm{e}^{-}$per gas molecule to the surface.

The gas sensing mechanism is a surface-dependent property; however, it is determined by the change in the electrical properties of the sensor materials after exposure to the test gas environments. The resistance showed inverse behavior with temperature for n-type metal oxides; however, for $\mathrm{ZnO}$, the adsorbed oxygen molecule is transferred to oxygen ions such as $\mathrm{O}_{2}{ }^{-}$(below $\left.100{ }^{\circ} \mathrm{C}\right) \mathrm{O}^{-}\left(100{ }^{\circ} \mathrm{C}\right.$ to $300{ }^{\circ} \mathrm{C}$ ) and $\mathrm{O}^{2-}$ (above $300{ }^{\circ} \mathrm{C}$ ) by extracting free electrons at a certain temperature, which leads to an increase in the resistance..$^{6,11,12,49,52,53}$ The adsorption of oxygen molecules arrests the conduction bond electrons and also reduces the density of conduction, forming a depletion layer on the surface of the $\mathrm{ZnO}$ nanowires. After that, the depletion layer obstructs the charge carrier transportation and leads to a change in the resistance of the $\mathrm{ZnO}$ nanowires. The following equations explain this process of oxygen ion formation:

$$
\begin{gathered}
\mathrm{O}_{2}(\text { ads })+\mathrm{e}^{-} \rightarrow \mathrm{O}_{2}^{-}(\text {ads }) \\
\mathrm{O}_{2}(\text { ads })+2 \mathrm{e}^{-} \rightarrow 2 \mathrm{O}^{-}(\text {ads }) \\
\mathrm{O}^{-}(\text {ads })+\mathrm{e}^{-} \rightarrow \mathrm{O}^{2-}(\text { ads })
\end{gathered}
$$

When reductive gases such as $\mathrm{CO}, \mathrm{C}_{2} \mathrm{H}_{5} \mathrm{OH}$, and $\mathrm{NH}_{3}$ are introduced into the chamber, the amount of gas adsorption and the reaction rate increase with increasing temperature. However, the gas adsorption rate becomes close to the gasdesorption rate at $100{ }^{\circ} \mathrm{C}$ and delivers maximum sensor response. Above $100{ }^{\circ} \mathrm{C}$, the reduced sensor response indicates a decrease in the quantitative adsorption of gases. Hence, the possible gas reaction with changes in the resistance of the hexagonal $\mathrm{ZnO}$ nanowires are as follows: ${ }^{52,53}$

$$
\begin{gathered}
\mathrm{CO}+\mathrm{O}_{\mathrm{ads}}{ }^{-} \rightarrow \mathrm{CO}_{2}(\text { gas })+\mathrm{e}^{-} \\
\mathrm{C}_{2} \mathrm{H}_{5} \mathrm{OH}+6 \mathrm{O}^{-} \rightarrow 2 \mathrm{CO}_{2}+3 \mathrm{H}_{2} \mathrm{O}+6 \mathrm{e}^{-}
\end{gathered}
$$




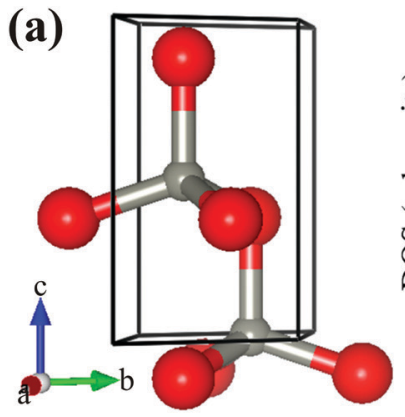

(c) $\mathrm{O}_{2} / \mathrm{ZnO}(10 \overline{1} 0)$

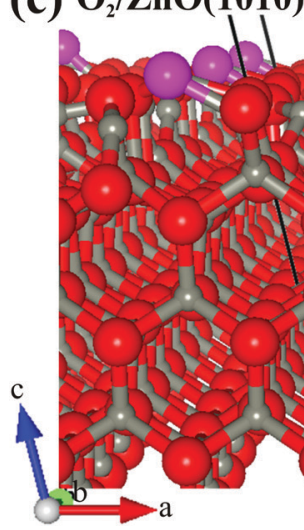

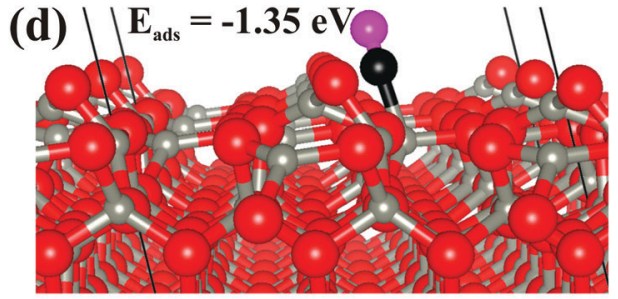

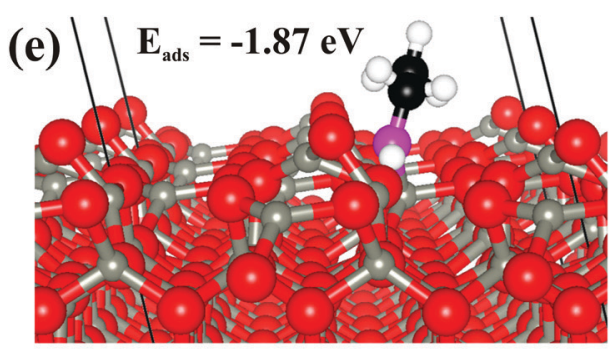

(f) $\rfloor E_{\text {ads }}=-2.11 \mathrm{eV}$

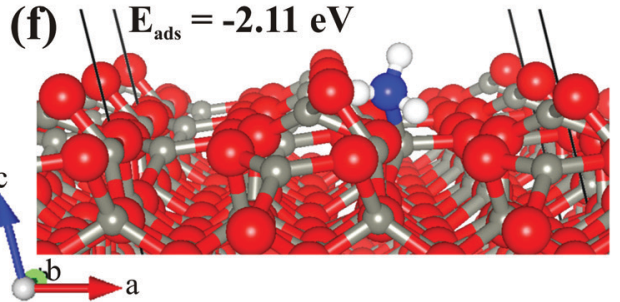

Fig. 7 Ball and stick models of (a) optimized hexagonal wurtzite bulk $\mathrm{ZnO}$ and (b) the corresponding partial density of states (PDOS); (c) surface structure of oxygen-covered (pink atoms) $\mathrm{O}_{2} /(10 \overline{1} 0)-(3 \times 3)$; $(d-f)$ lowest-energy adsorption structures of $\mathrm{CO}, \mathrm{C}_{2} \mathrm{H}_{5} \mathrm{OH}$, and $\mathrm{NH}_{3}$, respectively. Colour code: light grey $=\mathrm{Zn}$; red $=\mathrm{O}$; black $=\mathrm{C}$; blue $=\mathrm{N}$; white $=\mathrm{H}$, pink $=\mathrm{O}_{\mathrm{mol}}$.

$$
2 \mathrm{NH}_{3}+3 \mathrm{O}^{-} \rightarrow 3 \mathrm{H}_{2} \mathrm{O}+\mathrm{N}_{2}+3 \mathrm{e}^{-}
$$

Thus, $\mathrm{NH}_{3}$ reacts with adsorbed oxygen ions along the surface of the $\mathrm{ZnO}$ nanowires after exposure, which releases the captured electrons and results in decreases in the potential barrier and thickness of the space-charge layer. This consecutively decreases the resistance; hence, the gas sensing performance increases (ESI $\dagger$ ). Furthermore, the reducing $\mathrm{NH}_{3}$ gas influences the width of the space charge region by discharging extra electrons during the interaction, thus decreasing the resistance. ${ }^{6}$

This phenomenon largely depends on the total surface area accessible for the interaction of gas molecules and is expedited by textural (or grain) boundaries contributing a resistive barrier. The high resistance in the present hexagonal $\mathrm{ZnO}$ nanowires array is assigned to its larger number of grain boundaries and contacts established between the $\mathrm{ZnO}$ nanowires. The corresponding schematic is shown in Fig. 8. Vertically grown individual nanowires (left panel, Fig. 8) have a restricted total surface area and potential barriers (i.e., grain boundaries and point contacts). Therefore, most of the electrons from the $\mathrm{ZnO}$ nanowires directly flow with ease to the electrode. However, the hierarchically arranged $\mathrm{ZnO}$ nanowires (right panel, Fig. 8) furnished a much larger surface area and more potential barriers (i.e., grain boundaries and point contacts). Most of the electrons need to flow across the grain boundaries and transfer through the point contacts established in the hierarchical arrangement. Hence, the electrons suffer a larger barrier before reaching the electrode, expediting the gas sensing

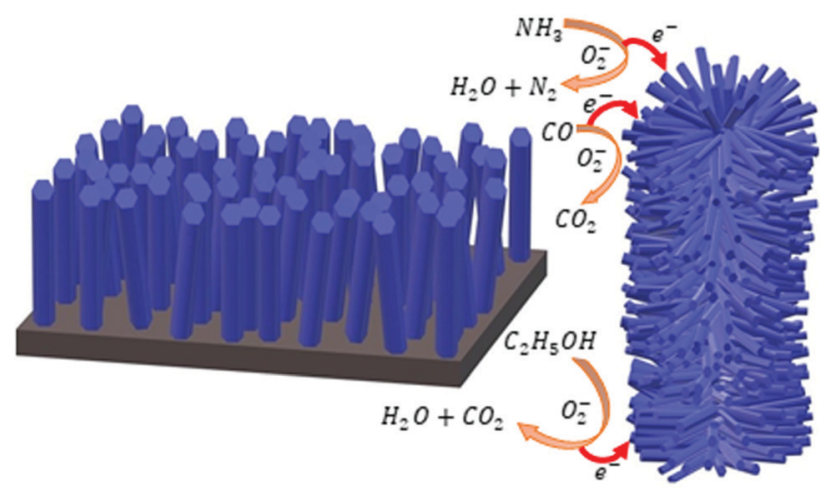

Fig. 8 Schematic representing the sensing mechanisms of vertically grown $\mathrm{ZnO}$ nanorods (left panel) and hierarchically grown $\mathrm{ZnO}$ nanowires (right panel).

mechanism. As a result, the present $\mathrm{ZnO}$ nanowires provided a higher response at a lower temperature than the various $\mathrm{ZnO}$ nanostructures reported in the literature.

\section{Conclusions}

In conclusion, hierarchical $\mathrm{ZnO}$ nanowires demonstrated excellent sensing performance for toxic gases. The $\mathrm{ZnO}$ nanowires delivered excellent sensing performance at the detection safety limits of $50 \mathrm{ppm}$ for $\mathrm{CO}, \mathrm{C}_{2} \mathrm{H}_{5} \mathrm{OH}$, and $\mathrm{NH}_{3}$ gases at a relatively 
low operating temperature of $100{ }^{\circ} \mathrm{C}$. The $\mathrm{ZnO}$ nanowires provided a maximum sensing response of $115 \mathrm{C}_{2} \mathrm{H}_{5} \mathrm{OH}$ was observed at the temperature of $100 \%$ for toxic $\mathrm{NH}_{3}$ gas and also delivered faster response and recovery times of 27 and $9 \mathrm{~s}$, respectively, for $50 \mathrm{ppm} \mathrm{NH}_{3}$ at the temperature of $100{ }^{\circ} \mathrm{C}$, which are better than those of the variety of pristine, defectcontrolled, and doped $\mathrm{ZnO}$ nanostructures. The complementary DFT analysis predicted the $\mathrm{CO}<\mathrm{C}_{2} \mathrm{H}_{5} \mathrm{OH}<\mathrm{NH}_{3}$ order of the binding strength of the gas molecules. The excellent sensing response of the hierarchical hexagonal $\mathrm{ZnO}$ nanowires is ascribed to the well-defined hexagonal morphology, clearly visible textural boundaries, single-crystalline nature, and good interconnections of the nanowires. The sensing performance can be further improved after forming tunable heteroarchitectures with metal nanoparticles.

\section{Conflicts of interest}

There are no conflicts to declare.

\section{Acknowledgements}

The authors are thankful to the UGC-DAE CSR Indore for their financial support of this research under grant no. CSR-IC-BL65/CRS-182/2017-18/189. R. S. D. and N. Y. D. acknowledge the AESM, DUO-India Professor Fellowship award for this work. SRR, RWC, and NYD acknowledge the UK Engineering and Physical Sciences Research Council (EPSRC) for funding (Grant No. EP/S001395/1). This work has also used the computational facilities of the Advanced Research Computing, Cardiff (ARCCA) Division at Cardiff University and HPC Wales. This work also utilize the facilities of ARCHER (http://www.archer.ac.uk), the UK's national supercomputing service via the membership of the HEC Materials Chemistry Consortium funded by EPSRC (EP/L000202).

\section{Notes and references}

1 H. Zhang, W. G. Chen, Y. Q. Li and Z. H. Song, Front. Chem., 2018, 6, 7.

2 L. Zhu and W. Zeng, Sens. Actuators, A, 2017, 267, 242-261.

3 R. S. Devan, R. A. Patil, J. H. Lin and Y. R. Ma, Adv. Funct. Mater., 2012, 22, 3326-3370.

4 J. H. Lin, R. A. Patil, R. S. Devan, Z. A. Liu, Y. P. Wang,

C. H. Ho, Y. Liou and Y. R. Ma, Sci. Rep., 2014, 4, 6967.

5 R. S. Devan, J. H. Lin, Y. J. Huang, C. C. Yang, S. Y. Wu, Y. Liou and Y. R. Ma, Nanoscale, 2011, 3, 4339-4345.

6 R. S. Ganesh, M. Navaneethan, V. L. Patil, S. Ponnusamy, C. Muthamizhchelvan, S. Kawasaki, P. S. Patil and Y. Hayakawa, Sens. Actuators, B, 2018, 255, 672-683.

7 C. Y. Chi, H. I. Chen, W. C. Chen and C. H. Chang, Sens. Actuators, B, 2018, 255, 3017-3024.

8 Y. J. Li, K. M. Li, C. Y. Wang, C. I. Kuo and L. J. Chen, Sens. Actuators, B, 2012, 161, 734-739.
9 R. S. Ganesh, E. Durgadevi, M. Navaneethan, V. L. Patil, S. Ponnusamy, C. Muthamizhchelvan, S. Kawasaki, P. S. Patil and Y. Hayakawa, Sens. Actuators, A, 2018, 269, 331-341.

10 G. S. T. Rao and D. T. Rao, Sens. Actuators, B, 1999, 55, 166-169.

11 R. S. Ganesh, E. Durgadevi, M. Navaneethan, V. L. Patil, S. Ponnusamy, C. Muthamizhchelvan, S. Kawasaki, P. S. Patil and Y. Hayakawa, J. Alloys Compd., 2017, 721, 182-190.

12 P. Cao, Z. Yang, S. T. Navale, S. Han, X. Liu, W. Liu, Y. Lu, F. J. Stadler and D. Zhu, Sens. Actuators, B, 2019, 298, 126850.

13 Y. Wang, X. N. Meng and J. L. Cao, J. Hazard. Mater., 2020, 381, 120944.

14 X. Huang, C. P. Li, L. R. Qian, M. J. Li, H. J. Li, X. C. Niu and B. H. Yang, Mater. Today Commun., 2019, 21, 100680.

15 P. R. Chikate, P. K. Bankar, R. J. Choudhary, Y. R. Ma, S. I. Patil, M. A. More, D. M. Phase, P. M. Shirage and R. S. Devan, RSC Adv., 2018, 8, 21664-21670.

16 P. R. Chikate, K. D. Daware, D. S. Gayhane, Y. R. Ma, R. J. Choudhary, S. I. Patil, M. A. More, D. M. Phase, S. W. Gosavi, P. M. Shirage and R. S. Devan, ChemistrySelect, 2018, 3, 7891-7899.

17 P. R. Chikate, K. D. Daware, S. S. Patil, P. N. Didwal, G. S. Lole, R. J. Choudhary, S. W. Gosavi and R. S. Devan, New J. Chem., 2020, 44, 5535-5544.

18 Y. Cai and H. Q. Fan, CrystEngComm, 2013, 15, 9148-9153.

19 P. Patil, G. Gaikwad, D. R. Patil and J. Naik, Bull. Mater. Sci., 2016, 39, 655-665.

20 N. Caicedo, R. Leturcq, J. P. Raskin, D. Flandre and D. Lenoble, Sens. Actuators, B, 2019, 297, 126602.

21 P. Rai, W. K. Kwak and Y. T. Yu, ACS Appl. Mater. Interfaces, 2013, 5, 3026-3032.

22 D. W. Wang, S. S. Du, X. Zhou, B. Wang, J. Ma, P. Sun, Y. F. Sun and G. Y. Lu, CrystEngComm, 2013, 15, 7438-7442.

23 S. J. Chang, W. Y. Weng, C. L. Hsu and T. J. Hsueh, Nano Commun. Netw., 2010, 1, 283-288.

24 H. Colak and E. Karakose, Sens. Actuators, B, 2019, 296, 126629.

25 K. M. Kim, H. R. Kim, K. I. Choi, H. J. Kim and J. H. Lee, Sens. Actuators, B, 2011, 155, 745-751.

26 A. Sharma, P. Bhojane, A. K. Rana, Y. Kumar and P. M. Shirage, Scr. Mater., 2017, 128, 65-68.

27 S. Kanaparthi and S. G. Singh, Mater. Sci. Energy Technol., 2020, 3, 91-96.

28 G. Kresse, J. Furthmüller and J. Hafner, Phys. Rev. B: Condens. Matter Mater. Phys., 1994, 50, 13181-13185.

29 P. E. Blöchl, Phys. Rev. B: Condens. Matter Mater. Phys., 1994, 50, 17953-17979.

30 J. P. Perdew, K. Burke and M. Ernzerhof, Phys. Rev. Lett., 1997, 78, 1396.

31 S. Grimme, J. Antony, S. Ehrlich and H. A. Krieg, J. Chem. Phys., 2010, 132, 19.

32 A. V. Krukau, O. A. Vydrov, A. F. Izmaylov and G. E. Scuseria, J. Chem. Phys., 2006, 125, 224106. 
33 G. Mattioli, F. Filippone, P. Alippi, P. Giannozzi and A. A. Bonapasta, J. Mater. Chem., 2012, 22, 440-446.

34 D. J. Cooke, A. Marmier and S. C. Parker, J. Phys. Chem. B, 2006, 110, 7985-7991.

35 G. W. Watson, E. T. Kelsey, N. H. de Leeuw, D. J. Harris and S. C. Parker, J. Chem. Soc., Faraday Trans., 1996, 92, 433-438. 36 P. W. Tasker, J. Phys. C: Solid State Phys., 1979, 12, 4977.

37 W. Tang, E. Sanville and G. A. Henkelman, J. Phys.: Condens. Matter, 2009, 21, 084204.

38 C. Y. Geng, Y. Jiang, Y. Yao, X. M. Meng, J. A. Zapien, C. S. Lee, Y. Lifshitz and S. T. Lee, Adv. Funct. Mater., 2004, 14, 589-594.

39 Z. W. Dong, C. F. Zhang, H. Deng, G. J. You and S. X. Qian, Mater. Chem. Phys., 2006, 99, 160-163.

40 R. Cusco, E. Alarcon-Llado, J. Ibanez, L. Artus, J. Jimenez, B. G. Wang and M. J. Callahan, Phys. Rev. B: Condens. Matter Mater. Phys., 2007, 75, 165202.

41 A. G. Milekhin, N. A. Yeryukov, L. L. Sveshnikova, T. A. Duda, C. Himcinschi, E. I. Zenkevich and D. R. T. Zahn, Appl. Phys. A: Mater. Sci. Process., 2012, 107, 275-278.

42 S. S. Lo and D. S. Huang, Langmuir, 2010, 26, 6762-6766.
43 Q. Simon, D. Barreca, A. Gasparotto, C. Maccato, E. Tondello, C. Sada, E. Comini, A. Devi and R. A. Fischer, Nanotechnology, 2012, 23, 025502.

44 L. W. Wang, Y. F. Kang, X. H. Liu, S. M. Zhang, W. P. Huang and S. R. Wang, Sens. Actuators, B, 2012, 162, 237-243.

45 J. Guo, J. Zhang, M. Zhu, D. X. Ju, H. Y. Xu and B. Q. Cao, Sens. Actuators, B, 2014, 199, 339-345.

46 Z. X. Yang, Y. Huang, G. Chen, Z. P. Guo, S. Y. Cheng and S. Z. Huang, Sens. Actuators, B, 2009, 140, 549-556.

47 T. Tharsika, M. Thanihaichelvan, A. Haseeb and S. A. Akbar, Front. Mater., 2019, 6, 122.

48 M. Shahabuddin, A. Sharma, J. Kumar, M. Tomar, A. Umar and V. Gupta, Sens. Actuators, B, 2014, 194, 410-418.

49 C. F. Li, C. Y. Hsu and Y. Y. Li, J. Alloys Compd., 2014, 606, 27-31. 50 J. H. Kim, A. Mirzaei, H. W. Kim and S. S. Kim, ACS Appl. Mater. Interfaces, 2019, 11, 24172-24183.

51 P. K. Baviskar, S. R. Rondiya, G. P. Patil, B. R. Sankapal, H. M. Pathan, P. G. Chavan and N. Y. Dzade, ACS Omega, 2020, 5, 6715-6724.

52 D. Zappa, E. Comini and G. Sberveglieri, Nanotechnology, 2013, 24, 444008.

53 C. F. Li, C. Y. Hsu and Y. Y. Li, J. Alloys Compd., 2014, 606, 27-31. 